\title{
A INFLUENCIA DOS MEIOS DE COMUNICAÇÃO EM MASSA NA TEORIA DA DECISÃO: UMA ANÁLISE DO DISCURSO LINGUÍSTICO NO NÍVEL PERLOCUCIONÁRIO
}

\author{
THE INFLUENCE OF MASS COMMUNICATIONS IN THE DECISION THEORY: AN ANALYSIS \\ OF LINGUISTIC DISCOURSE AT THE PERLOCUTIONARY LEVEL
}

\section{LA INFLUENCIA DE LOS MEDIOS DE COMUNICACIÓN EN MASA EN LA TEORÍA DE LA DECISIÓN: UN ANÁLISIS DEL DISCURSO LIGUÍSTICO EN EL NIVEL PERLOCUCIONARIO}

\section{Artur Cesar de Souza'}

\section{Mariana Ribeiro Santiago²}

Licença CC BY:

Artigo distribuído sob os termos Creative Commons, permite uso e distribuição irrestrita em qualquer meio desde que o autor credite a fonte original.

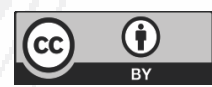

\begin{abstract}
Resumo: O presente artigo analisa, pelo prisma do discurso linguístico, no nível perlocucionário, a influência exercida pelos meios de comunicação de massa na teoria da decisão. A escolha do tema se justifica tendo em vista que os meios de comunicação de massa, por meio do seu próprio sistema linguístico, participam ativamente de uma rede de comunicação e de informação, visando não somente comunicar e informar, mas igualmente influir diretamente para a construção de uma nova ordem de ideias e de resultados de decisões. O estudo tem como objetivo analisar a influência do nível perlocucionário do discurso linguístico produzido pelos meios de comunicação em massa em relação à teoria da decisão judicial. Para tanto, num primeiro momento, visa-se demonstrar como os meios de comunicação de massa se apropriam do discurso linguístico para fins de manipulação da realidade social, e, na sequência, demonstra-se o efeito do discurso perlocucionário na delimitação do conteúdo hermenêutico da decisão judicial. O método de abordagem utilizado é o dialético jurídico, acompanhado do método de pesquisa bibliográfico. Em conclusão, entende-se que é preciso neutralizar a ingerência psicológica do discurso midiático, uma vez que a ilegitimidade dessa influência põe em risco o conteúdo hermenêutico da decisão judicial.
\end{abstract}

Palavras-chaves: 1. Mass media; 2. Comunicação; 3. Teoria da decisão; 4. Linguagem.

1 Pós-doutor em Direito pela Università Statale di Milano (Itália), pela Universidad de Valência (Espanha), pela Universidade Federal de Santa Catarina - UFSC e pela Faculdade de Direito da Universidade de Lisboa (Portugal). Doutor em Direito das Relações Sociais pela Universidade Federal do Paraná - UFPR. Juiz Federal Justiça Federal da Seção Judiciária do Paraná. Professor do Programa de Mestrado e Doutorado em Direito da Universidade de Marília - UNIMAR (SP). São Paulo (Brasil). E-mail: mariana@nbsadvogados.com.br.

2 Pós-Doutora em Direito pela Justus-Liebig-Universität Giessen (Alemanha). Doutora e Mestre em Direito pela Pontifícia Universidade Católica de São Paulo - PUCSP. Graduada em Direito pela Universidade Federal da Bahia - UFBA. Professora do Programa de Mestrado e Doutorado em Direito da Universidade de Marília - UNIMAR (SP). Editora-Chefe da Revista Argumentum. Advogada. São Paulo (Brasil). E-mail: mariana@nbsadvogados. com.br. 


\begin{abstract}
The present article analyzes, from the perspective of linguistic discourse, at the perlocutionary level, the influence exerted by the mass media in decision theory. The choice of theme is justified because the mass media, through its own linguistic system, actively participates in a communication and information network, aiming not only to communicate and inform, but also to directly influence the construction a new order of ideas and results of decisions. The objective of this study is to analyze the influence of the perlocutionary level of the linguistic discourse produced by the mass media in relation to judicial decision theory. First, it aims to demonstrate how the mass media appropriates linguistic discourse for the purpose of manipulating the social reality, then it analyzes the effect of the perlocutionary discourse in the delimitation of the hermeneutic content of the Judicial decision. The legal dialectic method is used, together with a bibliographic review. In conclusion, it is understood that it is necessary to neutralize the psychological interference of the media discourse, since the illegitimacy of this influence places the hermeneutic content of the judicial decision at risk
\end{abstract}

Keywords: 1. Mass media; 2. Communication; 3. Decision theory; 4. Language.

Resumen: El presente artículo analiza, por el prisma del discurso lingüístico, en el nivel perlocucionário, la influencia ejercida por los medios de comunicación en masa en la teoría de la decisión. La elección del tema se justifica teniendo en cuenta que los medios de comunicación en masa, por medio de su propio sistema lingüístico, participan activamente de una red de comunicación y de información, visando no solamente comunicar e informar, sino igualmente influir directamente para la construcción de una nueva orden de ideas y de resultados de decisiones. El estudio tiene como objetivo analizar la influencia del nivel perlocucionário del discurso lingüístico producido por los medios de comunicación en masa en relación a la teoría de la decisión judicial. Para tanto, en un primer momento, su objetivo es demostrar como los medios de comunicación en masa se apropian del discurso lingüístico para manipular la realidad social, y, en la secuencia, se demuestra el efecto del discurso perlocucionário en la delimitación del contenido hermenéutico de la decisión judicial. El método de abordaje utilizado es el dialéctico jurídico, acompañado del método de investigación bibliográfica. En conclusión, se entiende que es necesario neutralizar la injerencia psicológica del discurso mediático, una vez que la ilegitimidad de esa influencia coloca en riesgo el contenido hermenéutico de la decisión judicial.

Palabras-claves: 1. Mass media; 2. Comunicación; 3. Teoría de la decisión; 4. Lenguaje.

\title{
INTRODUÇÃO
}

A sociedade de informação e de comunicação é uma realidade inquestionável na conjuntura histórica atual. A interligação dos diversos setores de comunicação e de informação, sistemas próprios de relações sociais, tem por finalidade a construção de determinada realidade social e jurídica. Na verdade, não haveria qualquer sentido nos sistemas de relações sociais sem que um dos objetivos fosse justamente a construção de uma determinada ordem de ideias 
A sociedade brasileira, diante das grandes operações concernentes ao crime organizado (ex. Lava Jato, Zelotes, etc.), vivenciou e está vivenciando um importante momento de construção de uma nova realidade social e jurídica ditada pelos efeitos sociais e psicológicos desencadeados pelo discurso liguístico desenvolvido pelos mass media, que pode ter implicações na teoria da decisão.

O objetivo do presente trabalho é justamente reacender essa discussão, utilizando-se de um diálogo interdisciplinar entre a filosofia da linguagem (discurso linguístico) e o direito, para balizar a atividade do mass media e suas consequências sociais e psicológicas na teoria da decisão judicial. A necessidade de se contribuir, diante de tal quadro, para uma atuação judicial independente e técnica justifica o estudo ora pretendido.

Para tanto, o primeiro aspecto considerado no presente texto é que toda construção da realidade, seja no processo midiático, seja na teoria da decisão judicial, decorre de um ponto de partida em comum, a linguagem. Na sequência, procura-se encontrar um denominador comum entre o papel do discurso midiático na construção da realidade jurídica e a necessidade de neutralização de possíveis ilegítimas ingerências nesse entrelaçamento de comunicação e informação social.

O método de abordagem utilizado é o dialético jurídico, no qual se confrontam teoria e realidade sobre o tema para produção do resultado. 0 método de pesquisa é o bibliográfico, desenvolvido em obras jurídicas e áreas afins, num esforço de interdisciplinaridade.

\section{A LINGUAGEM COMO CONSTRUÇÃO DA REALIDADE SOCIAL E SUA APROPRIAÇÃO PELO DISCURSO MIDIÁTICO.}

Ao se ingressar no estudo dos efeitos produzidos pelos meios de comunicação em massa na teoria da decisão judicial, o primeiro aspecto a ser delineado é que toda construção da realidade, seja no processo midiático, seja no processo jurisdicional, decorre de um ponto em comum, a linguagem. 
Nas várias fases da pré-história e da história, os seres humanos realizaram transformações distintivas e determinantes no sistema de comunicação. $O$ primeiro passo foi o lento processo que se verificou na passagem da idade dos sinais para a idade das palavras e da linguagem. Num segundo passo, chega-se à era da escritura. A transição para a imprensa escrita foi mais veloz e conduziu à era da comunicação de massa, particularizada por uma transformação muito rápida. A característica essencial desse processo de transição não está configurada pela evolução tecnológica, mas pelo aperfeiçoamento da linguagem, o que permitiu à sociedade humana armazenar, requerer e transmitir informação. Isso permitiu à espécie humana um desenvolvimento muito maior que as demais espécies, uma vez que toda a mudança de fase proporcionou um aumento significante na capacidade da espécie humana de inovar e de acumular solução aos problemas colocados pelo ambiente físico e social. ${ }^{3}$

$\mathrm{Na}$ época antiga, Gorgias de Leontini (484-375) referiu-se de modo clarividente à essência da linguagem, em sua obra "Encomio de Helena", afirmando: "La palavra es una gran dominadora, que, con un cuerpo pequeñíssimo e invisible, realiza obras por demás divinas". Na perspectiva de Mauricio Beuchot, essa afirmação de Gorgias de Leontini significa que "el lenguaje es tan poderoso que con una palabra más pequeña que una mosca, esto es, con un 'sí o un 'no', puede construir reinos y desatar guerras".. Segundo afirmou Gottfried Herder (17741803), em sua obra "Sobre o Surgimento da Linguagem" (1772): "a linguagem é muito mais que um instrumento para o manejo da realidade, é, melhor dizendo, algo que constitui a realidade". ${ }^{5}$

Graças à linguagem existe a realidade do mundo. Mas a linguagem fechada nos signos e nas relações apenas entre os signos, numa semiótica sem semântica, sem o seu dizer do mundo ou sem referência a ele de qualquer modo que seja, seria um acervo de sinais sem qualquer conteúdo e, portanto, sem qualquer significação possível ${ }^{6}$

3 DEFLEUR, Melvin L.; BALL-ROKEACH, Sandra J. Teorie delle comunicazion di massa. Bologna: II Mulino, 1995. p. 250.

4 BEUCHOT, Mauricio. História de la filosofia del lenguaje. México: Fondo de Cultura Económica, 2005. p.13.

5 BEUCHOT, Mauricio. História de la filosofia del lenguaje. p. 145.

6 NEVES, A. Castanheira. O actual problema metodológico da interpretação jurídica. Coimbra: Coimbra Editora, 2003. pp. 251-252. 
$\mathrm{Na}$ ótica de Castanheira Neves, a referência é o resultado da unidade referencialmente constitutiva entre a linguagem e o mundo, pois não havendo uma oposição fundamental entre ambos na funcionalidade essencial entre eles - se o mundo é correlato funcional na linguagem, a linguagem existe já no intencional dizer o mundo, na comunicante ação no mundo -, todos os objetos referidos são constituídos na sua determinação objetiva por meio da prática linguística de certa comunidade linguística (a prática linguística da Lebenswelt (mundo da vida), desde logo, com as suas determinantes objetivações próprias). ${ }^{7}$

$\mathrm{Na}$ realidade, se o mundo é pressuposto ontológico da realidade (das coisas e dos acontecimentos), o mundo, como originário da existência objetivado, emerge de uma unidade objetivante (unidade de uma experiência e da sua expressão) em que participa constitutivamente a dimensão linguística. ${ }^{8}$ É na linguagem que vem exprimir-se toda a compreensão ôntica ou ontológica do "mundo da vida" (Lebenswelt). ${ }^{9}$

A linguagem é extremamente importante para se produzirem determinados efeitos nas relações de comunicação social, em especial efeitos psicossociais. Com essa afirmação inicial, pretende-se optar pela perspectiva de que a realidade não tem por fundamentação uma garantia transcendental do conhecimento.

Dito de outra maneira, não se pode comparar nossas proposições supostamente descritivas com um mundo independente da linguagem em que se acha descrito. Segundo Rorty, não há maneira, como dizia Wittgenstein, de introduzir entre a linguagem e seu objeto, de distinguir a girafa em si mesma de nossas maneiras de falar das girafas. ${ }^{10}$

A condição comunicativa do homem, na visão de Mauricio Beuchot, valendose dos ensinamentos de Aristóteles (Política):

\footnotetext{
está vinculada à sua natureza social, e esta à sua natureza racional, a qual evita que ele seja simplesmente agregário como o animal. O homem possui um grande repertório de signos; possui, sobretudo, o signo lingüístico, e dele se vale para comunicar a seus semelhantes o que lhes é agradável ou desagradável, o que lhes é proveitoso ou nocivo, e, de maneira mais específica, o que considera justo ou injusto.11
}

$7 \quad$ NEVES, A. Castanheira. O actual problema metodológico da interpretação jurídica. pp. 258-259.

8 NEVES, A. Castanheira. $\mathbf{O}$ actual problema metodológico da interpretação jurídica. p. 274.

9 RICOUER. Paul. O conflito das interpretações - ensaios de hermenêutica. Tradução Hilton Japiassu. Rio de Janeiro: Imago Editora Ltda., 1969. p. 14.

10 VIVES ANTÓN, Tomás S. Más allá de toda duda razonable. Teoria \& Derecho - Revista de Pensamento Jurídico. n. 2, jun.-dez. Valencia: Tirant lo Blanch, 2007. p. 170.

11 BEUCHOT, Mauricio. História de la filosofia del lenguaje. p. 21. 
Na verdade, não existe comunicação sem linguagem, assim como não há linguagem sem comunicação. E não havendo comunicação, não há também o conhecimento da realidade.

Conhecer os modos pelos quais as pessoas compartilham ou não conseguem compartilhar os significados por meio do uso da linguagem é indispensável para compreender como surge a comunicação e quais as suas consequências sobre o público. ${ }^{12}$

Ao tempo de Platão, restava muito claro a importância do caráter convencional do significado. Para Platão,

... a interpretação subjetiva da realidade é uma questão social mais que individual. Segundo
Platão, o conhecimento do mundo no qual vivemos depende não somente disso que per-
cebemos pessoalmente, com os nossos sentidos, mas também pelo fato de que entramos
em acordo com os nossos semelhantes em relação a significados condivisos relativos ao
mundo externo.13

Portanto, a "construção social da realidade" não se limita a uma percepção individual meramente sensorial, mas decorre principalmente dos significados codivididos ou acordados socialmente.

Deve-se, ainda, considerar o caráter comunitário da linguagem, pois ela sempre pertence a uma determinada comunidade linguística, sendo constituída e manifestada por meio de uma comunicação-dialógica nessa comunidade.

Não era outra coisa que Humboldt queria dizer

\begin{abstract}
quando sublinhava que a linguagem pertence "necessariamente a dois", que assim o momento da alteridade the é essencial. De tal modo isso que não só o originário e comunicativo "ser um com outro" da existência humana se revela também de forma evidente na linguagem - nela temos o "coencontrar-se" e o "cocompreender" dessa coexistência - como ainda nela se oferece "expressamente" o imediato comum dessa mesma coexistência. Pelo que, digamo-lo também com Gadamer, a linguagem não pertence à esfera do "eu", mas à esfera do "nós". 14
\end{abstract}

12 "Lo studioso che si occupa seriamente di comunicazioni di massa deve conoscere la natura delle parole e degli altri simboli, le convenzioni linguistiche, la natura del significato e il rapporto tra le conoscenze apprese tramite il linguaggio e il comportamento". (DEFLEUR, Melvin L.; BALL-ROKEACH, Sandra J. Teorie delle comunicazion di massa. p. 250).

13 DEFLEUR, Melvin L.; BALL-ROKEACH, Sandra J. Teorie delle comunicazion di massa. p. 257.

14 NEVES, A. Castanheira. O actual problema metodológico da interpretação jurídica. p. 277. 
A linguagem, todavia, não é um dado absoluto e neutro, mas um produto cultural que deve ser estudado numa perspectiva histórica e social. ${ }^{15}$ Nessa perspectiva cultural, a linguagem não tem por único fim a comunicação das ideias, senão também o de produzir paixões, evitar ações, etiquetar fenômenos. ${ }^{16}$

Segundo Rousseau, em seu livro "Ensayo sobre el o oigen de lãs lenguas":

\begin{abstract}
(...) a linguagem - como a maioria pensa - é para expressar ou comunicar as paixões. Para as necessidades servem mais os movimentos e os gestos... Assim, pois, a linguagem não é para expressar nossas necessidades, senão nossas paixões e emoções. Efetivamente, as necessidades não unem os homens, mas os separam e os afastam entre si; ao contrário, são as paixões as que os aproximam. E se a linguagem é para manifestar paixões, isto se faz melhor com a linguagem figurada: para expressar a admiração perante a natureza e seus fenômenos, para abrandar o coração de uma jovem, para provocar ódio ou medo, servem mais os "tropos" ou figuras de linguagem, isto é, a linguagem figurada, que a literal e direta. ${ }^{17}$
\end{abstract}

Para Giambattista Vico (1668-1774), a natureza da linguagem é mais do que ser um instrumento para a expressão e a comunicação entre os homens; revela algo constitutivo do ser humano, e por isso o acompanha em sua evolução histórica, segundo as diferentes etapas que ele assinala: divina (teocrática e sacerdotal, com idioma sensorial, hieroglífico), heróica (aristocrática, imaginária e simbólica) e humana (monarquia e intelectual)"..18

Na ótica de Wilhelm von Humbtoldt (1767-1835), a linguagem tem também um papel muito importante na evolução do homem. Tanto em nível individual, ou ontogenético, como em nível coletivo, ou filogenético, a linguagem é o encarregado da formação do homem, tanto do indivíduo como dos povos. A linguagem intervém na formação das cosmovisões ou visões do mundo. A linguagem é ação, mais que obra, dada sua dinamicidade, que escapa a toda "esclerotización" ou intento de aprisioná-la. ${ }^{19}$

A dependência do ser humano com respeito às relações entre objeto, signo mediador e consciência interpretante é algo insuperável..$^{20}$ Por isso a palavra ou signo linguístico tem como designativo direto e imediato a afecção da mente ou conteúdo mental (conceito e afeto), pois se vai primeiro à realidade como 15 TARUFFO, Michele. La motivazione della sentenza civile. Padova: CEDAM, 1975. p. 86.

16 BEUCHOT, Mauricio. História de la filosofia del lenguaje. p. 122.

17 BEUCHOT, Mauricio. História de la filosofia del lenguaje. p. 140.

18 BEUCHOT, Mauricio. História de la filosofia del lenguaje. p. 128.

19 BEUCHOT, Mauricio. História de la filosofia del lenguaje. p. 149.

20 PROSS, Harry. Estructura simbólica del poder - teoría y práctica de la comunicación pública. Barcelona: Editorial Gustavo Gili S.A., 1980. p. 22. 
conhecida, e depois à realidade como tal. E esse conhecimento é acompanhado de elementos volitivos e afetivos. ${ }^{21}$

A mídia, ao realizar sua comunicação por meio da linguagem, o faz por meio dessa conjugação de elementos volitivos ou afetivos, ou seja, de um duplo sentido ou múltiplo-sentido que ao mesmo tempo procura mostrar e ocultar. Esse sentido mostrado-oculto encontra-se inserido numa estrutura de significação denominada de símbolo, na qual um sentido direto, primário e literal designa acréscimo, outro sentido indireto, secundário e figurado só pode ser apreendido pelo primeiro. Essa circunstância das expressões de duplo sentido constitui o campo hermenêutico midiático, o qual procura criar efeitos psicossociais nas demais relações com o intuito de construir uma realidade social segundo a hermenêutica construída pelos mass media.22

Na realidade, a linguagem dos meios de comunicação em massa não se esgota na informação transmitida, pois ela se engendra numa série de ressonância e normatização das práticas sociais. ${ }^{23} \mathrm{~A}$ linguagem midiática, longe de se limitar a reproduzir passivamente a realidade tal como ela é, "(...) contribuye activamente a configurarla $y$, de algún modo, a producirla (...)". ${ }^{24} \mathrm{E}$ para produzir de algum modo a realidade social, deve fazê-lo por meio de um processo de produção e mutação das significações conotativas (ideológicas) da comunicação social. Assim, o discurso ${ }^{25}$ dos meios de comunicação em massa encontra-se vinculado aos diversos setores do todo social.

Essa vinculação, por sua vez, está carregada por uma dimensão políticoideológica que se pode denominar de semiologia do poder ou semiologia política, e que estabelece os pressupostos da produção discursiva a partir de suas ligações com as relações de força da sociedade, bem como pelas determinações ideológicas que a constituem historicamente. ${ }^{26}$

$21 \quad$ BEUCHOT, Mauricio. História de la filosofia del lenguaje. p. 23.

22 SORLIN, Pierre. Mass media. Tradução José Luis Garcia. Londres: Celta Editora, 1997. p. 15

23 WARAT, Luis Alberto. O direito e sua linguagem. 2. ed. Porto Alegre: Sergio Fabris, 1995. p. 15.

24 COROMINAS, Jordi. Ética primera - aportación de x. zubiri al debate ético contemporáneo. Bilbao: Editorial Desclée de Brouwer, S.A., 2000. p. 49.

25 "Il discurso è qualcosa di più di una conversazione o di uno scritto: è un modo di parlare e scrivere. Regolare il discorso vuol dire porre un'insieme di regole formali e informali su ciò che può essere detto, come deve essere detto e chi lo si può dire (...). Dato che il linguagio è il mezzo principale attraverso cui esprimiamo, gestiamo ed evochiamo le emozioni, regolare un discorso significa regolare l'emozione. La conseguenza finale è una regolazione della condotta. Quando una forma discorsiva è stabilita come pratica-tipo, essa diventa uno strumento per riprodurre la diseguaglianza, in quanto può essere usata non soltanto per regolare il pensiero e le emozioni, ma per identificare gli altri e, perciò, anche per difendere i confini”. (ALTHEIDE, David. L., I mass media, il crimine e il 'discorso di paura'. In: La Televisione del Criminine. A cura di Gabrio Forti e Marta Bertolino. Milano: V\&P Università, 2005. p. 297).

26 ROCHA, Leonel Severo. A problemática jurídica: uma introdução transdisciplinar. Porto Alegre: Sergio Antonio Fabris, 1985. p. 35. 
A semiologia política, portanto, ao se desvencilhar da dicotomia língua e fala, inclina-se para uma teoria de formação discursiva composta de implicações ideológicas. Na verdade, o objeto do discurso não se encontra delimitado nas palavras, na análise interna do discurso, em sua estrutura intralinguística, mas pelas condições de possibilidade dos discursos. ${ }^{27}$

A análise pragmática vinculada à temática ideológica "impõe a necessidade de realizar leituras ideológicas dos discursos dos meios de comunicação em massa". ${ }^{28}$ As expressões simbólicas passam a ser um mecanismo importante para que os meios de comunicação em massa exteriorizem sua experiência do mundo, sendo que todo esse conteúdo simbólico possui seu advento no elemento da linguagem ${ }^{29}$, daí por que a análise do sentido oculto do discurso linguístico produzido pelos meios de comunicação em massa é um pressuposto indispensável para se compreender a construção da realidade social.

Pela hermenêutica, como trabalho de pensamento, é possível decifrar o sentido oculto inserido no sentido aparente, isto é, desdobrar os níveis de significação implicados na significação literal. Símbolo e interpretação tornam-se assim conceitos correlativos. ${ }^{30}$ É decifrando as astúcias do desejo que se descobre o desejo na raiz do sentido da reflexão.

A tarefa da hermenêutica é a de mostrar que a existência só vem à palavra, ao sentido e à reflexão, procedendo a uma contínua interpretação de todas as significações que se manifestam no mundo da cultura. ${ }^{31} \mathrm{~A}$ tarefa da hermenêutica é justamente demonstrar essa ambiguidade que por vezes está por detrás do discurso da mídia, esse duplo sentido encontrado no simbolismo midiático.

Os meios de comunicação em massa, cientes do papel do trabalho interpretativo, utilizam-se muitas vezes do discurso linguístico midiático para delimitar o campo hermenêutico da construção social da realidade, gerando importantes efeitos no âmbito psicossocial. ${ }^{32}$ Ao massificarem a informação

27 ROCHA, Leonel Severo. A problemática jurídica: uma introdução transdisciplinar. p. 35

28 "A pragmática permite compreender que a ideologia é um fator indissociável da estrutura conceitual explicitada nas normas gerais." ( WARAT. L. A. O direito e sua linguagem. p. 47).

29 SORLIN, Pierre. Mass media. p 15

30 SORLIN, Pierre. Mass media. p. 15

31 RICOUER. Paul. O conflito das interpretações - ensaios de hermenêutica. Tradução Hilton Japiassu. Rio de Janeiro: Imago, 1969. p. 23.

32 Segundo Paul Ricouer, entende-se por hermenêutica a teoria das operações da compreensão em sua relação 
pelo seu discurso linguístico comunicacional, procuram delimitar o campo hermenêutico da interpretação do fato e do direito, o que significa também um implicador negativo na aferição da verdade processual.

Cotidianamente, se é bombardeado por uma comunicação "persuasiva" uma atrás da outra. Estas solicitações não convencem por meio de dar e receber argumentações e pelo debate, mas por meio da manipulação dos símbolos e das emoções mais profundas. ${ }^{33}$

Os meios de comunicação, utilizando-se do discurso linguístico de seus textos audiovisuais, seja pela retórica, pela poesia ou pelo erotismo, pretendem persuadir, agradar ou seduzir, dando o instrumental necessário para a interpretação do círculo comunicativo ou do círculo semiótico. ${ }^{34}$

A retórica, a poesia e o erotismo são de fato estratégias textuais e, ao mesmo tempo, estratégias de análise: todos os textos utilizam-nas de um modo ou de outro, com gradação diferenciada. ${ }^{35}$ Romper com o campo delimitador desse círculo hermenêutico delineado pelos meios de comunicação em massa passa a ser o grande desafio para se alcançar a neutralização dos efeitos negativos dos mass media.

Especialmente diante das questões criminais, os meios de comunicação em massa, rádio, televisão e jornais, pela retórica, pretendem direcionar a interpretação dos fatos e do direito, sugestionando a opinião pública e de certa forma o próprio juiz do processo no momento de proferir sua decisão. ${ }^{36}$

com a interpretação dos textos (RICOUER, Paul. Interpretação e ideologias. Tradução Hilton Japiassu. Rio de Janeiro: Livraria Francisco Alves Editora S.A.,1977. p.17).

33 PRATKANIS, Anthony R.; ARONSON, Elliot. Psicologia delle comunicazioni di massa. Bologna: II Mulino, 1996. p. 15.

34 SILVERSTONE, R. Perché studiare i media? Bologna: II Mulino, 2002. p. 60

35 SILVERSTONE, R. Perché studiare i media? p. 60

36 "No obstante la inclusión de estos contenidos en los programas informativos no deja de suscitar ciertos inconvenientes. Los telediarios, sendo los programas que en mayor medida contribuyen a la formación de la opinión, suelen concentrar sus informaciones en hechos singularmente violentos y espectaculares y con frecuencia guardan relación directa con el resultado inmediato de la investigación-detención del autor, expulsión o extradición - o con la condena; pero su formato impide facilitar explicaciones de fondo sobre el hecho delictivo y, lo que es más importante, las razones de la actuación de los tribunales, lo que dificulta notablemente la comprensión del contexto.

Por otro lado, es la inclusión de estos contenidos en programas de entretenimiento y variedades lo que suscita los mayores reparos, porque este tipo de formatos se apartan abiertamente de las reglas de la ética profesional por las que se rigen los programas informativos, cuya finalidad es garantizar una información creíble: contraste de las fuentes, selección de las noticias según la importancia y el interés de las mismas, y separación entre información y opinión. 
A retórica torna-se um importante recurso linguístico utilizado pelos meios de comunicação em massa nessa cadeia discursiva, sendo ao mesmo tempo:

\begin{abstract}
uma prática e um instrumento crítico, que permite falar bem e em vista de um escopo, mas também entender e ensinar como fazê-lo do melhor modo possível. Retórica, memória e invenção, inseparavelmente ligadas, num tempo formavam a base de uma cultura pública oral que permitia expressar-se, aumentava a criatividade, notabilizava o pensamento, com o fim de instruir, comover e agradar.37
\end{abstract}

Acima de tudo, a retórica é persuasão, é delimitação hermenêutica. ${ }^{38}$ Tratase de uma linguagem orientada para ação, com a intenção de alterar posições e orientações e influenciá-las, mas é também voltada para a modificação de valores e comportamentos, a comover ou de todo modo dominar.

Segundo Roger Silverstone, a linguagem dos meios de comunicação em massa é a retórica, que tem por pressuposto um desejo de influenciar e aceitar a existência de uma hierarquia na estrutura da comunicação midiática. ${ }^{39}$

Cícero, em seu terceiro livro, "Do Orador", já discutia estilo, metáfora, sintaxe, ritmo, enfim o efeito subconsciente do estilo sobre o auditório e os seus lapsus, de uma maneira geral as linhas de argumentação. ${ }^{40}$

Cícero fala de digressão, repetição, redução, hipérbole, atenuação, ironia, indagações retóricas, distinção, correção, preparação do auditório para aquilo que se está para fazer, identificação de parte do público, personificação e assim por diante. Fala, efetivamente, de uma preparação hermenêutica conjugada com a delimitação do campo interpretativo de um determinado fato ou circunstância. Elenca figuras de palavras (repetitio, adiunctio, progressio, revocatio, gradatio, conversio, contrarium, dissolutum, declinatio reprehensio, exclamatio, imminutio,

En unos casos se hacen públicos nombres o fotos de personas buscadas por la policía, presentándoles ante la opinión pública como criminales, sin que estas personas hayan sido todavía condenadas (se convierte la búsqueda de delincuentes en un entretenimiento, en el que se hace partícipe al espectador, como si se tratase de un simple concurso); en otros se recurre a técnicas de investigación o interrogatorio no autorizadas por la ley (dector de mentiras), buscando la complicidad de testigos, acusados e, incluso, de sus abogados; en otros, en fin, se detecta una cierta desconfianza en lo que vayan hacer los tribunales, intentando descubrir, al margen del proceso judicial, a los 'culpables reales'”. (LÓPEZ ORTEGA, Juan J. Información y justicia. In: Justicias y Medios de Comunicación, Cuadernos de Derecho Judicial, Madrid, XVI, 2006. p. 121 e 122).

38 A persuasão, para Anthony R. Pratkanis e Elliot Aronson, é uma força misteriosa e potente nas mãos daqueles que sabem manuseá-la, essa pode ser empregada para constranger e exigir ações estranhas e freqüentemente deploráveis sem nenhuma razão aparente. (PRATKANIS, Anthony R.; ARONSON, Elliot. Psicologia delle comunicazioni di massa. p. 27).

39 SILVERSTONE, R. Perché studiare i media? p.62.

40 SILVERSTONE, R. Perché studiare i media? p. 68. 
imago): todos exemplos de "efetiva expressão (...) que são como as armas que se usam para minar e quase para ferir, ou se manejam somente para um espetáculo de beleza" (ibidem, III, LIV, 206). ${ }^{41}$

\section{Como afirma Reinhart Koselleck:}

(...) entre as proposições mais chamativas sobre as coisas e uma história lingüística que se inclina à permanência, há que registrar, na verdade, um problema geral de toda retórica; esta constrói-se sobre argumentos repetíveis para ter efeito num momento singular. Heinrich Lausberg assinalou: Quando os topóis retóricos não são examinados como acontece normalmente, senão de forma singular, ou como algo mal compreendido, então são eles sobrevalorizados; quando, ao contrário, são concebidos como fórmulas vazias e repetíveis, então são eles substimados, e também são mal-entendidos. O que vale para a retórica, vale também para o conjunto da pragmática: trata-se de distinguir entre o conteúdo de inovação e as estruturas de repetição, de sopesar uma e outras para julgar de modo adequado a coisa. Precisamente, a singularidade de um discurso determinado que teve êxito, ou que uma argumentação seja algo único em seu gênero, baseiam-se na arte de usar e combinar elementos repetíveis de linguagem, já conhecidos, de tal maneira que se ouça algo único, ou novo. E para conseguir isso, deve-se sempre ter presente a diferença entre a configuração lingüística e o estado objetivo das coisas. A ordem de matar (ou a aprovação do assassinato), ou a notícia da morte não são idênticas à própria morte. 42

As raízes da retórica encontram-se no desejo de comunicar pela própria retórica, de alcançar um auditório e identificar-se com esse, mobilizar os lugares comuns unificados pela cultura do tempo e mover-se, criativamente, para além desses. Os lugares comuns são, de fato, lugares de invenção e inovação tanto quanto de memória e de testemunhança. ${ }^{43}$

Examinar os discursos linguísticos dos meios de comunicação em massa do ponto de vista retórico significa compreender como os significados são construídos e adaptados de modo plausível, agradável e persuasivo. Os meios de comunicação em massa utilizam-se da retórica para, mediante argumentos repetitivos, influenciar a construção da realidade psicossocial no momento da prolação da decisão judicial pelo juiz. Sem dúvida, tal influência pode ser extremamente perniciosa para o resultado de um processo justo e équo.

\section{O NÍVEL PERLOCUCIONÁRIO DO DISCURSO DOS MEIOS DE} COMUNICAÇÃO EM MASSA E SUA REPERCUSSÃO NA TEORIA DA DECISÃO

\section{A teoria da decisão não cuida da decisão como realidade social, mas trata} das regras para sua construção, das condições de possibilidade. Nessa linha,

41 SILVERSTONE, R. Perché studiare i media? pp. 68-69.

42 KOSELLECK, Reinhart. Estructuras de repecticón en el lenguaje y en la historia. In: Revista de Estudios Políticos, Madrid, n. 134, diciembre/2006, (17-34). p. 33.

43 SILVERSTONE, R. Perché studiare i media?. p. 71. 
encara o problema da decidibilidade como produto da incidência contínua do direito na convivência, considerada como sistema de conflitos intermitentes ${ }^{44}$.

Na concepção clássica, o termo decisão está ligado a processos deliberativos individuais, nos quais se opta por uma possibilidade, abandonando-se as demais, como um ato final. Modernamente, tem sido reconhecida uma maior complexidade em tal processo, em que a justificação da opção constitui a questão de sua legitimidade ${ }^{45}$.

A atual visão alargada da decisão reflete a existência de um procedimento dentro do processo, muito mais complexo do que uma deliberação individual, mas como componente de uma situação de comunicação, num sistema interativo global, pois é ato referido a outrem, em diferentes níveis recorrentes ${ }^{46}$.

Nesse sentido, Tercio Sampaio Ferraz Jr. ${ }^{47}$ considera que a finalidade última da decisão é a absorção da insegurança:

\footnotetext{
A nosso ver, a finalidade imediata da decisão está na absorção de insegurança, no sentido de que, a partir das alternativas incompatíveis, enquanto premissas relativamente inseguras da decisão, novas alternativas são obtidas, sem a necessidade, em princípio, de um retorno constante às incompatibilidades primárias, tendo em vista decisões subseqüentes.
}

Na teoria da decisão, mostra-se um quadro em que a decisão aparece como um sistema de procedimentos regulados, cabendo a cada agente agir de certo modo, o que gera segurança sobre tal comportamento, tanto do ponto de vista lógico-formal, como ideológico. Os procedimentos institucionalizados como controle da decisão devem, assim, neutralizar a pressão dos fenômenos sociais sobre o sistema jurídico. O que se decide, por fim, é o conflito institucionalizado ${ }^{48}$. Dentro desse contexto, logicamente, não há espaço para a interferência dos meios de comunicação em massa.

Atualmente é aceito nos gabinetes editoriais que o objetivo dos jornais, dos discursos ou dos programas de rádio e de televisão não é o de simplesmente

44 FERRAZ JR., Tercio Sampaio. Introdução ao estudo do direito: técnica, decisão, dominação. 6. ed. rev.e ampl. São Paulo: Atlas, 2012. p. 285.

45 FERRAZ JR, Tercio Sampaio. Introdução ao estudo do direito: técnica, decisão, dominação. p. 286. PERELMAN, Chaïm. Retóricas. Tradução Maria Ermantina Galvão G. Pereira. São Paulo: Martins Fontes, 1999. p. 349.

46 FERRAZ JR., Tercio Sampaio. Introdução ao estudo do direito: técnica, decisão, dominação. p. 287.

47 FERRAZ JR., Introdução ao estudo do direito: técnica, decisão, dominação. pp. 43-44.

48 FERRAZ JR, Tercio Sampaio. Introdução ao estudo do direito: técnica, decisão, dominação. pp. 297 e 321. 
transmitirem informações ou difundirem opiniões. ${ }^{49} \mathrm{Na}$ verdade, a linguagem dos mass media preenche três funções: a) a função da reprodução cultural ou da presentificação das tradições (é nessa perspectiva que Gadamer desenvolve sua hermenêutica filosófica); b) a função de integração social ou da coordenação dos planos de diferentes atores na interação social (é nessa perspectiva que se desenvolve a teoria do agir comunicativo); e c) a função da socialização da interpretação cultural das necessidades (é nessa perspectiva que C.H. Mead projetou sua psicologia social). ${ }^{50}$

Para Maurice Mereleau-Ponty, a linguagem sempre apresenta uma tripla função: $1^{\circ}$ ) função representativa; $2^{\circ}$ ) função expressiva; $3^{\circ}$ ) função de apelo ao outro. ${ }^{51}$ Assim, pode-se afirmar que "dizer algo a alguém" e "compreender o que é dito" baseiam-se em pressuposições mais complicadas e muito mais pretensiosas do que o simples "dizer (ou pensar)".52

Mais uma vez, o alerta deve ser feito: não se deve confundir os signos da linguagem, que só remetem a outros signos no interior do mesmo sistema e fazem com que a língua não possua mais mundo, como não possui tempo e subjetividade, com o discurso linguístico que é sempre discurso a respeito de algo: refere-se a um mundo que pretende descrever, expressar ou representar e estabelecer os limites de sua interpretação. Enfim, a língua não é senão a condição prévia da comunicação, para qual ela fornece seus códigos; mas é no discurso que todas as mensagens são trocadas..$^{53}$

O discurso se dá como evento, pois algo acontece quando alguém fala. Essa perspectiva de discurso como evento ocorre a partir do momento em que se realiza a passagem de uma linguística da língua ou do código a uma linguística do discurso ou da mensagem. A distinção advém de Ferdinand Saussure e Louis Hjelmslev. O primeiro distingue a 'língua' e a 'fala'; o segundo distingue o 'esquema' e o 'uso'. . $^{54}$

49 SORLIN, Pierre. Mass media. p.23.

50 HABERMAS, Jürgen. Consciência moral e agir comunicativo. 2. ed. Rio de Janeiro: Tempo Brasileiro, 2003. p.41.

51 MERLEAU-PONTY, Maurice. Merleau-Ponty na Sorbonne: resumo de cursos. Tradução Constança Marcondes Cesar. Campinas: Papirus, 1990. p.37.

52 HABERMAS, Jürgen. Consciência moral e agir comunicativo. p 42.

53 RICOUER. Paul. O conflito das interpretações - ensaios de hermenêutica. p. 46.

54 RICOUER. Paul. O conflito das interpretações - ensaios de hermenêutica. p. 46 
Afirmar que o discurso é um evento significa dizer que o discurso é realizado temporalmente e no presente. O evento, nesse sentido, é a vinda à linguagem de um mundo mediante o discurso. É no discurso que todas as mensagens são trocadas. Nesse aspecto, somente o discurso possui não somente um mundo, mas o outro, outra pessoa, um interlocutor ao qual se dirige. Nesse aspecto o evento é fenômeno temporal da troca, o estabelecimento do diálogo, que pode travar-se, prolongar-se ou interromper-se..$^{55}$

Ao se mencionar o caráter do evento do discurso, apenas se revelou um dos dois polos de sua constituição. O segundo aspecto importante do discurso é o da significação. É a tensão entre esses dois polos (evento e significação) que configura o discurso como obra, a dialética da fala e da escrita.

Na verdade, segundo Paul Ricouer, todo discurso é efetuado como evento e compreendido como significação. $O$ que se deseja compreender não é o evento, na medida em que é fugidio, mas sua significação que permanece. Essa articulação é o núcleo de todo o problema hermenêutico. ${ }^{56}$

Para conseguir elucidar o que "é dito" de modo mais completo, a hermenêutica deve recorrer não somente à linguística - mesmo compreendida no sentido de linguística do discurso, por oposição à linguística da língua -, mas também à teoria do Speech-Act, encontrada em Austin e em Sarle. O ato do discurso, segundo esses autores, é constituído por uma hierarquia de atos subordinados, distribuídos em três níveis: a) ao nível do ato locucionário ou proposicional: ato de dizer; b) ao nível do ato (ou força) ilocucionário: aquilo que se faz ao dizer; c) ao nível do ato perlocucionário: aquilo que se faz pelo fato de falar. "Se eu digo a alguém para fechar a porta, faço três coisas: a) refiro o predicado de ação (fechar) a dois argumentos (alguém e a porta): ato de dizer; b) mas eu digo essa coisa a alguém com a força de uma ordem e não de uma constatação, de um desejo ou de uma promessa: é o ato ilocucionário; c) enfim, posso provocar certos efeitos, tais como o medo, pelo fato de dar uma ordem a alguém; esses efeitos fazem do discurso uma espécie de estímulo que produz certos resultados: é o ato perlocucionário. ${ }^{57}$

55 RICOUER. Paul. O conflito das interpretações - ensaios de hermenêutica. p. 46

56 RICOUER. Paul. O conflito das interpretações - ensaios de hermenêutica. p. 47.

57 RICOUER. Paul. O conflito das interpretações - ensaios de hermenêutica. pp. 47-48. 
Segundo Paul Ricouer, o ato perlocucionário constitui o aspecto menos inscritível do discurso, e caracteriza, preferencialmente, o discurso oral. A ação perlocucionária é justamente aquilo que, no discurso, é o menos discurso. É o discurso como estímulo. Neste caso, o discurso manifesta-se não pela trucagem do reconhecimento, por meu interlocutor, de minha intenção, mas, de certa forma, de um modo energético, por influência direta sobre as emoções e as disposições afetivas do interlocutor. Assim, o termo significação tem uma acepção bastante ampla, recobrindo todos os aspectos e todos os níveis da exteriorização intencional que torna possível, por sua vez, a exteriorização do discurso na obra e nos escritos. ${ }^{58}$

Segundo Mauricio Beuchot, baseando-se em John Langsbaw Austin (1911-1960):

\begin{abstract}
Toda manifestação lingüística é um ato que envolve outros três atos como dimensões suas: é, por sua vez, um ato locucionário, um ato ilocucionário e um ato perlocucionário. A dimensão de ato locucionário é a mais primitiva e elementar; dá-se na expressão lingüística enquanto esta possui certo sentido e certa referência. Logo vem a dimensão de ato ilocucionário, que é mais elaborada e se dá na expressão lingüística enquanto esta possui uma força característica, segundo o tipo de intenção que a anima: asseverar, ordenar, desejar, advertir etc. Finalmente aparece a dimensão de ato perlocucionário, que se dá na expressão lingüística enquanto ela produz certo efeito psicológico no ouvinte: o informa, o persuade, o não persuade, inclusive o surpreende ou lhe desconcerta. 59
\end{abstract}

Os meios de comunicação em massa, ao realizarem seu discurso linguístico sobre determinados fatos, o fazem sob a égide dos níveis locucionários, ilocucionários e principalmente perlocucionários.

Pelo nível perlocucionário pretendem provocar, por meio da retórica, certos efeitos, seja na opinião pública, seja no juiz do processo, dentre eles, o efeito medo ou paúra na opinião pública e o efeito irresponsabilidade ou conivência à impunidade no juiz. Na verdade, o nível perlocucionário do discurso midiático pode atingir, acima de tudo, aquilo que Lacan denomina de inconsciente coletivo. ${ }^{60}$

58 RICOUER. Paul. O conflito das interpretações - ensaios de hermenêutica. pp. 48-49.

59 BEUCHOT, Mauricio. História de la filosofia del lenguaje. p. 250.

60 Há um ponto no pensamento lacaniano que interessa particularmente e em especial à essa argumentação: ‘“.(..) a formação do inconsciente efetuada pelas relações simbólicas que passam pelo sentido de um 'outro' universal que cria o discurso. As cadeias significantes deslizam-se para uma mensagem criada efetivamente pelo 'grande outro'. Porém, é o 'outro' do desejo, da enunciação que se dirige ao inconsciente, a um inconsciente inato, universal e 
A figura do "inconsciente coletivo" de Lacan sugere uma pergunta que não quer calar: se se poderia aplicar a prática psicanalítica de Lacan às "fantasias mass-midiáticas" com a finalidade de se encontrar uma possível patologia coletiva difundida, dia a dia, e repetida, ano a ano, por meio de uns significantes (e símbolos) muito bem elaborados. ${ }^{61}$

Empiricamente, pode-se constatar, de certa forma, a importância do nível perlocucionário no inconsciente coletivo. $\mathrm{Na}$ análise estatística feita na Itália por Gerlinda di Smaus, referente à sensação de insegurança e do aumento da criminalidade, observa-se que 71\% dos entrevistados têm a impressão de que a criminalidade se encontra em franca ascensão, apesar de não coincidir a sensação coletiva com os dados oficiais sobre a criminalidade. ${ }^{62}$

coletivo. Este inconsciente, considerado por Lacan, determina um simbolismo universal absolutamente diferenciado do simbolismo do consciente... Esse 'inconsciente social' que se desloca em sucessivas identificações acaba impregnando a complexidade de níveis e instituições sociais. Como se do movimento da razão hegeliana se tratasse, só que ao inverso, o inconsciente - enquanto o 'outro' silenciado - atravessa a história e suas produções intelectuais e materiais"). (MUÑOZ, Blanca. La cultura global - medios de comunicación, cultura e ideologia en la sociedad globalizada. Madrid: Pearson Prentice Hall, 2005. p. 287).

61 "Chegado a este ponto, é nos permitido fazer uma pergunta: se se poderia aplicar a prática psicanalítica de Lacan às 'fantasias mass-midiáticas' com a finalidade de se encontrar uma possível patologia coletiva difundida, dia-adia, e repetida, ano-a-ano, por meio de uns significantes (e símbolos) muito bem elaborados? Na atualidade, a evolução da psicanálise como teoria social dos 'traumatismos fictícios', que os 'medios' estão realizando, supõem um giro copernicano em relação à mesma 'formação' do inconsciente privado. Os 'outros' discursos são os agentes, inclusive, do desmoronamento do inconsciente único e individual. A cada vez maior interação no grupo afirma e desencadeia sintomas que já não provêm somente da saúde mental do indivíduo. Como afirmava Marcuse, em nosso tempo já não existe o 'complexo de Édipo' à maneira da época em que Freud escrevia. Atualmente a realidade e seus meios de comunicação são os encarregados de socializar as crianças e os jovens. O desaparecimento da fronteira entre o interior e o exterior é uma das características definitórias da existência de massificação. A introjecção de crenças imaginárias dá lugar em Lacan à sua teoria do repúdio (forclusión). A 'forclusión' é aquilo que não foi admitido no simbólico e se converte em alucinação na existência real. Este processo de psicose nos leva a pensar no núcleo de múltiplos 'esquemas' argumentativos e 'fabuladores' dos meios de comunicação. Aqui seria interessante repetir a frase de Freud: 'As fantasias produzem-se por uma combinação inconsciente de coisas vistas e de coisas escutadas. Em último sentido, e extrapolando a colocação freudiano-lacaniano, poder-se-ia dizer que as mensagens dos 'medios' podem ser interpretadas como as fantasias do inconsciente desse gigantesco 'outro' que as gestiona. A combinação de imagens é a combinação de quem produz e programa os temas por tratar, porém também é a evidência de suas fantasias inconscientes". (MUÑOZ, Blanca. La cultura global - medios de comunicación, cultura e ideologia en la sociedad globalizada. pp. 288-290).

62 Segundo a pesquisadora: "Un semplice indicatore della crazione di un clima de opinione riguardo alla criminalità risulta già dal confronto di questi due aspectti negativi. La sensazione generale di essere minacciati, como già si è visto con lo 'statement' "ci si debe difendere dai pericoli", è stata confermata proprio dal fatto che, secondo il 71,3\% del campione, negli ultimi anni vi è stato un aumento della criminalità, secondo il 18,1\% la criminalità non ha subito variazioni e secondo il 5\% è diminuita (tabella10). Al contrario, solo il 2,1\% degli intervistati considera molto alta la probalità di rimanere vittima di un crime nella zona in cui abita, il 9,3\% la considera'alta', il 54\% 'scarsa' ed il $29,3 \%$, addirittura 'minima'. Abbiamo poi formulato la domanda aperta: 'Ha mai pensato di quali crimini e in quali circostanze lei stesso potrebbe diventare vittima? (tabela 23). Nella maggior parte dei casi (23,2\%) gli intervistati temono di rimanere vittima di reati della circolazione stradale. Al secondo posto sta la rapina (11,6\%), segue il furto (8,7\%). La possibilità di essere vittima di truffa à valutada con una percentuale del 7,1\%, più alta della probabilità subire un furto con scasso (6,4\%). II pericolo di essere vitima di lesioni personali (3,4\%), di delitti sessuali (2,4\%) o di atti terroristici (0,9\%), viene stimato molto piú lieve, contrariamente dunque all, immagine fornita dai mass media. In ogni caso se ne può dedurre che la rappresentazione della criminalità non serve affatto ad una funzione pedagogica a difesa dei cittadini, ma piuttosto ad attivare un atteggiamento di difesa di fronte ad un pericolo perceptio come latente. Essa serve a mantenere la consapevolezza del problema della criminalità distraendo in 
No Brasil, essa sensação de constante aumento generalizado da criminalidade também está enraizada no "inconsciente coletivo" em decorrência do efeito perlocucionário do discurso retórico linguístico midiático. Em que pese a sensação generalizada de aumento da criminalidade e a forte impressão de que a qualquer momento o cidadão poderá ser vítima de um delito de natureza grave, em pesquisa verificou-se que apenas em $10 \%$ dos municípios brasileiros concentram-se $71 \%$ dos crimes de homicídio no país. ${ }^{63}$

\title{
Segundo David L. Altheide:
}

\begin{abstract}
existem duas razões pelas quais o crime está tão propagado na televisão americana e, de modo crescente, em todo o mundo. A primeira, como dito, é que o crime está conexo ao medo, sendo a melhor parte dos formatos de entretenimento. A segunda é que o crime é muito fácil de se tratar e por isso se adapta bem à programação e às limitações pessoais das televisões locais: como observou o vice-presidente de uma rede de televisões locais, "as notícias sobre o crime são as mais fáceis, as mais velozes, as mais econômicas, as mais eficazes para as televisões. Os novos diretores amam o crime...". Um claro limite desta estrutura é que os crimes mais raros, como homicídio e lesões graves, recebem a maior parte do espaço informativo, enquanto aqueles mais freqüentes, como furtos e roubos, são pouco tratados. Como conseqüência, os expectadores (e os leitores) têm a impressão de que crime significa necessariamente "crime violento". Está amplamente provado que esta percepção do "problema criminal" encoraja o eleitor a defender "legislações repressivas", como a obrigação de condenações severas após o terceiro crime cometido ("three strikes and you are out") e a pena de morte.64
\end{abstract}

tal modo da altri importani problemi politico-sociali'. (SMAUS, Di Gerlinda. L'immagine della criminalità nei mass media contenuti e significati simbolici. In: La Questione Criminale - rivista di ricerca e dibattio su devianza e controllo sociale, Anno IV, n. 1., gennaio-aprile, 1978 (351-377). p. 369).

Kerner e Feltes (Medien, Kriminalitätsbild und Öffentlichkeit) também puderam demonstrar numa ampla pesquisa sobre comunicação relativa à criminalidade nos meios de comunicação, que a informação na mídia é distorcida: "Essi hanno analizzato per i mesi di giugno e di novembre del 1977 quattro giornali di Francoforte di diversi livelli e hanno individuato 1.248 unità di indagine, ovvero notizie, relative alla criminalità. L'informazione sui reati nei quotidiani di diversi livelli era relativamente omogenea. Nella parte interregionale dei giornali, dal 21 al $23 \%$ circa delle notizie di criminalità riguardavano reati contro la vita; la quota di questo gruppo di reati nella statistica criminale della polizia (PKS) era invece pari solamente allo 0,08\%, del totale; dal 5,2\% fino all 10,4\% delle notizie si riferiva a rapine o, rispettivamente, a estorsioni (PKS 0,6\%); dal 2,8\% a 5,9\% a lesioni personali (PKS 4,1\%), dall'11,5\%, fino al 20,8\% a tratta di esseri umani o rispettivamente sequestri di persona (PKS 0,003\%); per contro solo dal 2,7\% fino al 9,7\% delle notizie riguardavano i furti (PKS 65,4\%). Ciò rende chiara l'estrema distorsione della comunicazione. Si parla raramente di reati che sono di massa secondo le statistiche della polizia, como il furto, molti dei quali sono furti in negozi o ipotesi di furto leve, mentre si parla molto dei relativamente rari casi di tratta di esseri umani e di sequestro di persona. Una ulteriore analisi dei media di Amburgo mostra risultati simili". (KURY, Helmut. Mass media e criminalità: l'esperienza tedesca. Tradução Carlo Ruga Riva e Arianna Cremona. In: La Televisione del Crimine, a cura di Gabrio Forti e Marta Bertolino, Milano, V\&P Università, 2005, (319-357). p.332).

63 Estudo divulgado nesta terça-feira (29) pela Rede de Informação Tecnológica Latino Americana (Ritla) mostra que a violência no país está concentrada em apenas $10 \%$ dos municípios. Os dados da pesquisa "Mapa da violência dos municípios brasileiros 2008", referentes ao ano de 2006, mostram que nada menos do que $73,3 \%$ do total de homicídios ocorridos no Brasil foram cometidos nos 556 municípios mais violentos. Atualmente, o Brasil possui 5.564 municípios. (http://intranet.jfpr.gov.br/clipping/materia .php?codigo=5841, 30.01.2008).

64 ALTHEIDE, D. L. I mass media, il crimine e il "discorso di paura". In: Gabrio Forti; Marta Bertolino (Org.). La 
Mas para que o discurso linguístico midiático possa alcançar sua pretensão perlocucionária, não é suficiente apenas a hipervaloração quantitativa e qualitativa dos fatos delituosos. O medo (paúra) não é decorrente apenas dessa inconsistência informativa.

Para que a pretensão midiática tenha algum sucesso, é necessário que esteja presente na opinião pública um importante fator de acoplamento que é a necessidade de o cidadão colocar-se em lugar do outro, isto é, no lugar da vítima de um crime massificadamente transmitido pelos mass media. ${ }^{5} \mathrm{Na}$ verdade, quanto mais frequentemente os telespectadores vejam representações da violência, tanto mais percebem a probabilidade de se transformarem em vítimas de ações violentas. ${ }^{66}$

A experiência do crime, da dor e do ressentimento provocado pelo fato delituoso, de colocar-se em lugar do outro (vítima do delito), correspondente àquilo que Max Scheler denominará de proximidade da consciência coletiva:

as consciências só são separadas pela sua corporeidade, pelo conjunto dos instrumentos de
que se servem; a 'corporeidade' é de certo modo a matéria sensível com a ajuda da qual se
apreende a si mesmo ou ao outro. Mas o sensível puro num conteúdo, sua intenção, pode
ser compartilhado pelo outro. Assim, numa queimadura, só o sujeito que se queima pode
sentir a acuidade sensível da dor; mas tudo o que uma queimadura representa - ameaça do
fogo, perigo para a integridade do corpo, o sentido de dor - pode ser comunicado ao outro
e sentido pelo outro; é então a mesma forma, o mesmo conteúdo do sentimento que é televisione del criminine. Milano: V\&P Università. p. 289.

65 "Altri studi hanno mostrato che la paura e la percezione di sé come vittima sono influenzate dal senso di appartenenza. II crimine e i pericoli per l'ordine pubblico - e perciò per tutti i cittadini comuni - restano la fonte principale della paura, ma, come si rileva in tutto il libro, mutano nel corso del tempo i suoi oggetti. Sempre, comunque, a essere preso di mira, è l'altro, l'outsider, l'estraneo, lo straniero. Schwalbe e altri hanno mostrato che questa costruzione dell'alterità è parte del processo sociale con cui un gruppo dominante definisce l'esistenza di un gruppo subalterno. Ciò richiede l'instaurazione e la percezione di gruppo dei propri confini simbolici, che sorgono attraverso processi istituzionali fondati sulle situazioni e sugli scambi quotidiani, ivi compresi quelli linguistici, discorsivi, narrativi, dialogici. La conoscenza e la capacità di usare un 'sapere condiviso' implica una socializzazione formale e informale, grazie alla quale i membri del gruppo incassano il capitale culturale con cui acquistare consenso, devozione e senso di appartenenza. Parte di questo linguaggio coinvolge il discorso di paura”. (ALTHEIDE, D. L. I mass media, il crimine e il “discorso di paura”, pp. 296-297).

66 "Quanto più freqüentemente i telespettatori vedono rappresentazioni della violenza, tanto più avvertono la probabilità di diventare vittime di azioni violente".

É bem verdade que existe pensamento em contrário: "Un più recente studio inglese di Williams e Dickinson è arrivato, sulla base di analisi multivariate, al risultato che ci sia una signiifcativa relazione tra la lettura di giornali, che trattano, per lo più, la criminalità violenta, e il corrispondente timore del crimine. Tuttavia non è stata riscontrata alcuna relazione con indicatori comportamentali della paura del crimine, come il non uscire di casa al calare della notte. Sacco conclude: 'sul piano empirico, per quanto sia verosimile che molta della paura colletiva del crimine sia prodotta o aggravata dalla esposizione ai mass media, la validità o persino l'esistenza stesssa di tale nesso causale non hanno ancora trovato compiuta dimostrazione". (KURY, H. Mass media e criminalità: l'esperienza tedesca. p. 346). 
vivido por meio de uma outra matéria. O sentido, a intenção do sentimento (o que constitui o essencial deste) é semelhante para as duas consciências; há isolamento do sentido mas não isolamento de consciências. ${ }^{67}$

Segundo Scheler, não se pode realmente ser o outro, mas se pode tornar o outro intencionalmente, pode-se atingir o outro por meio de suas manifestações expressivas pelas quais ele se dá a nós. Na dor não se percebe o outro como não se representa para si sua dor material e sensível; o elemento intencional do sentido só é generalizado em relação ao sentimento verdadeiro. Não se tem a experiência real do outro enquanto não se ligam as significações de um sentimento ao fato mesmo de viver essas significações. ${ }^{68}$

Como já teve oportunidade de advertir Alexandro Baratta, o medo da criminalidade representa um sentimento geral de insegurança e de ansiedade não ligado apenas aos fenômenos criminais e, de todo modo, relativamente independente da específica percepção da possibilidade de se transformar em vítima dos delitos no próprio quarteirão. A desproporção entre o medo genérico da criminalidade e a valoração do perigo concreto de se transformar em vítima de delitos (nítida vantagem do primeiro) resulta também pela já recordada pesquisa sobre a reação social ao comportamento desviante, etc. ${ }^{69}$

Portanto, é pela sensação de medo (paúra), acoplada ao receptor - colocarse em lugar do outro -, que o efeito perlocucionário pretendido pelos meios de comunicação em massa terá eficácia no âmbito da "opinião pública". Contudo, o mais preocupante é que os resultados obtidos pelo nível perlocucionário do discurso midiático no "inconsciente coletivo" (sensação de aumento da criminalidade, medo, paúra) não se restringem ao âmbito da opinião pública.

Os efeitos do nível perlocucionário do discurso linguístico dos mass media podem desencadear consequências em "cascata" extremamente drásticas, isto é, produzir um mecanismo social de pressão no resultado do processo jurisdicional, a fim de que a sentença a ser proferida no âmbito do juízo criminal tenha correspondência à delimitação hermenêutica traçada previamente pela retórica discursiva proveniente dos mass media.

67 MERLEAU-PONTY, Maurice. Merleau-Ponty na Sorbonne: resumo de cursos. Tradução Constança Marcondes Cesar. Campinas: Papirus, 1990. p.50.

68 MERLEAU-PONTY, Maurice. Merleau-Ponty na Sorbonne: resumo de cursos. p. 51.

69 BARATTA, Alessandro. Problemi sociali e percezione della criminalità. In: Dei Delitti e delle Pene. Revista di studi sociali, storici e giuridici sulla questione criminale. Anno I, n. 1, gennaio-aprile, 1983, Roma, (15-37). p. 25. 
Por meio desse mecanismo intimidador decorrente do nível perlocucionário, pretende-se transferir ao Poder Judiciário a responsabilidade por eventual sensação de aumento da impunidade, quando a decisão não esteja em conformidade aos limites hermenêuticos traçados no discurso midiático.

Os riscos para um processo público com todas as garantias são importantes, principalmente pelo fato de que os limites hermenêuticos estabelecidos pelos meios de comunicação em massa e introduzidos no âmbito do nível perlocucionário de seu discurso não apresentam qualquer compromisso com a verdade ou falsidade, pois o código binário dos mass media está circunscrito ao informar ou não informar.

\section{CONCLUSÃO}

A importância da linguagem na relação existente entre mass media e a ciência jurídica, em especial, em relação à teoria da decisão judicial, é inegável, com especial ênfase para o caráter coletivo e cultural da linguagem e o poder da retórica.

Após revisitar algumas concepções teóricas sobre os principais fatores de composição da linguagem, chega-se à conclusão de que os efeitos do nível perlocucionário do discurso linguístico dos mass media pode desencadear consequências em "cascata" extremamente perigosas para o resultado de um processo équo e justo, isto é, produzir um mecanismo social de pressão no resultado do processo jurisdicional, a fim de que a sentença a ser proferida no âmbito do processo judicial tenha correspondência à delimitação hermenêutica traçada previamente pela retórica discursiva proveniente dos mass media.

Faz-se necessária uma união de esforços dos profissionais da ciência da comunicação, da psicologia e da ciência jurídica para solucionar essa problemática existente no âmbito das relações sociais, a fim de se neutralizar possíveis efeitos perniciosos do nível perlocucionário do discurso midiático na teoria da decisão.

A decisão que se contamina pela interferência do discurso midiático, além de gerar profunda insegurança social, contribui para uma quebra na credibilidade e na estabilidade do Poder Judiciário, como instituição, o que se mostra prejudicial, em última instância, ao próprio desenvolvimento nacional. 


\section{REFERÊNCIAS DAS FONTES CITADAS}

ALTHEIDE, D. L. I mass media, il crimine e il "discorso di paura". In: Gabrio Forti; Marta Bertolino (Org.). La televisione del criminine. Milano: V\&P Università, 2005.

BARATTA, A. Problemi sociali e percezione della criminalità. Dei delitti e delle pene. Rivista di Studi Sociali, Storici e Giuridici Sulla Questione Criminale. ano I, n. 1, jan.-abr. Roma, 1983.

BEUCHOT, M. História de la filosofia del lenguaje. México: Fondo de Cultura Económica, 2005. COROMINAS E. J. Ética primera - Aportación de X. Zubiri al debate ético contemporáneo. Bilbao: Desclée de Brouwer, 2000.

DEFLEUR, M. L.; BALL-ROKEACH, S. J. Teorie delle comunicazion di massa. Bologna: Il Mulino, 1995. FERRAZ JR., Tercio Sampaio. Direito, retórica e comunicação. 2 ed. São Paulo: Saraiva, 1997. FERRAZ JR, Tercio Sampaio. Introdução ao estudo do direito: técnica, decisão, dominação. 6. ed. rev.e ampl. São Paulo: Atlas, 2012.

FORTI, G.; BERTOLINO, M. (a cura di). La televisione del criminine. Milano: V\&P Università, 2005. HABERMAS, J. Consciência moral e agir comunicativo. 2. ed. Rio de Janeiro: Tempo Brasileiro, 2003. KOSELLECK, R. Estructuras de repecticón en el lenguaje y en la historia. Revista de Estudios Políticos. Madrid, n. 134, dez. 2006.

KURY, H. Mass media e criminalità: l'esperienza tedesca. Tradução Carlo Ruga Riva e Arianna Cremona. In: Forti, Gabrio; Bertolino, Marta (a cura di). La televisione del crimine. Milano: V\&P Università, 2005.

LÓPEZ ORTEGA, J. J. Información y justicia. Cuadernos de Derecho Judicial. Justicias y Medios de Comunicación. N. 16. Madrid: Consejo General del Poder Judicial, 2006.

MERLEAU-PONTY, Maurice. Merleau-Ponty na Sorbonne: resumo de cursos. Tradução Constança Marcondes Cesar. Campinas: Papirus, 1990.

MUÑOZ, B. Cultura y comunicación - Introducción a las teorías contemporáneas. Barcelona: Barcanova, 1989.

NEVES, A. C. O actual problema metodológico da interpretação jurídica. Coimbra: Coimbra Editora, 2003.

PERELMAN, Chaïm. Retóricas. Tradução Maria Ermantina Galvão G. Pereira. São Paulo: Martins Fontes, 1999.

PROSS, H. Estructura simbólica del poder - Teoría y práctica de la comunicación pública. Barcelona: Gustavo Gili, 1980. 
RICOUER, Paul. Interpretação e ideologias. Tradução Hilton Japiassu. Rio de Janeiro: Francisco Alves, 1977.

RICOUER, P. O conflito das interpretações - Ensaios de hermenêutica. Tradução Hilton Japiassu. Rio de Janeiro: Imago, 1969.

ROCHA, L. S. A problemática jurídica: uma introdução transdisciplinar. Porto Alegre: Fabris, 1985.

SILVERSTONE, R. Perché studiare i media? Bologna: Il Mulino, 2002.

SMAUS, D. G. L'immagine della criminalità nei mass media contenuti e significati simbolici. La Questione Criminale - Rivista di Ricerca e Dibattio su Devianza e Controllo Sociale, ano IV, n. 1, jan.-abr. 1978.

SORLIN, P. Mass media. Tradução José Luis Garcia. Londres: Celta, 1997.

TARUFFO, M. La motivazione della sentenza civile. Padova: Cedam, 1975.

VIVES ANTÓN, T. S. Más allá de toda duda razonable. Teoria \& Derecho - Revista de Pensamento Jurídico. n. 2, jun.-dez. Valencia: Tirant lo Blanch, 2007.

WARAT, L. A. O direito e sua linguagem. 2. ed. Porto Alegre: Fabris, 1995. 